\title{
In vitro fertilisation
}

Of all the problems in biomedical ethics those associated with the new techniques of in vitro fertilisation (IVF) are among the most complex. Some of the major ones are addressed in this issue of the journal but there are, of course, a host in addition. It is perhaps useful to differentiate several categories of these problems. At least five such categories suggest themselves: those related to taboos about sexuality; problems associated with conflicts of interests; those pertaining to the moral status of the embryo/fetus; worries stemming from moral concern about the nature of mankind; and difficulties relating to the resolution of moral conflict concerning these issues.

All our attitudes to reproductive matters are liable to be influenced by our sexual taboos and there can be few people however 'liberated' who do not retain such taboos (those who doubt this should ask themselves what they feel about the varieties of non-procreative incest between consenting adults - and why). In some societies infertility - itself the reason for the development of IVF - is overtly regarded as a stigma, a punishment for some blameworthy attribute. Even where such taboo-laden feelings are socially suppressed and inchoate they may express themselves in powerfully hostile attitudes especially where the infertility is caused by previous sexually transmitted disease (STD) or associated with 'non-standard' sexual attitudes or predilections in the woman concerned. Sexual taboos should surely have no role in the assessment of these issues unless it is clear that a particular taboo is morally relevant in a particular case (for example, if it were possible to show that a woman's lesbianism was likely to be a reliable predictor of significant harm to her child or children).

Conflicts of interests encompass perhaps the most difficult category of medico-moral problem in this area. To be considered are the woman who provides the ovum, the man who provides the sperm and the woman in whose uterus the embryo is to develop; the embryo-fetus throughout its development, and the child and adult that it may become; society as a whole; and last but not least the doctors and scientists and others involved in the procedures. The relevant interests have to be considered in relation to each of the many possible procedures which the 'standard' techniques of IVF have made possible, including IVF where egg or sperm or both have been donated; surrogate motherhood; and experimentation on the embryo/fetus. It may be useful when reviewing the various but by no means endless permutations thrown up by such considerations to do so in the context of two dichotomies: is the embryo intended to survive or is it to be killed or 'allowed to die'? And in the case of embryos intended to survive is the intervention under consideration therapeutic (realistically intended to benefit the health of the person-to-be) or is it nontherapeutic (intended to benefit others): while quite considerable risks may be justifiable if the potential benefits to the subject of therapeutic intervention (the person-to-be) are judged to outweigh these risks, only negligible risks would generally be acceptable if these are imposed by medical interventions designed not in the subject's interests but in the interests of others.

Questions about the moral status of the human embryo-fetus are central to medico-moral analysis of IVF and its related activities. There are three standard philosophical positions (with many variants). The mainstream Roman Catholic position (shared, of course, by many non-Catholics) is that all living human beings from the moment of conception (fertilisation) are morally equal (1). To kill a human embryo or to do research on it and then kill it is thus as wrong as to do this to a fully developed human being; it could certainly not be justified by reference to the benefit that other human beings would be expected to obtain as a result of such killing. Standard objections to this position include the fork that either it is 'speciesist' in giving unjustified weight to mere membership of the human species or that (in seeking to avoid this charge) it puts weight that cannot be borne upon the argument from potential; objectors usually add that moment-ofconception views offend against widely and strongly held moral intuitions that a newly fertilised egg and early embryo are obviously not of the same moral value as fully developed human beings.

A second standard position is that the development of sentience (here the ability to experience pain or suffering) is what establishes moral equivalence (2). In this context Singer, who has argued previously for this Benthamite position (3) adds in this issue of the 
journal that if the now widely accepted medical view that brain death is sufficient moral justification for removal of organs in otherwise living human bodies is sound then by parity of reasoning similar removal of organs and presumably other experimentation should be morally acceptable before the onset of brain life in the developing human embryo-fetus. Standard objections to the moral-equivalence-starts-withsentience position include the claim that mere ability to experience suffering is inadequate as a basis for distinguishing our moral duties (if any) to animals from our (indubitable) moral duties to each other; and that the position thus offends against a widely and strongly held moral intuition that people have moral obligations to each other of a totally different order from those which they may or may not have towards animals.

A third position is that what counts for moral equivalence with ordinary mature human beings is the existence of 'personhood'. It is sometimes objected that such views are vacuous in that to be a person simply means to be an entity which has moral equivalence to ordinary human beings. Usually, however, philosophers advocating personhood criteria are offering necessary or even necessary and sufficient criteria for such moral equivalence. John Locke (4) proposed self-awareness as a necessary condition of being a person and this position is reflected more recently by Tooley (5). Harris offers an admittedly unargued definition of a person as 'any individual capable of valuing its own life' adding that Lockean self-consciousness will be a necessary condition of such a capability (6). Objections to 'personhood' views of moral equivalence are numerous and include their disparity, the inadequate philosophical argumentation on which they are based and their conflict with widely and strongly held moral intuitions that newborn babies are morally equivalent to mature human beings even though they are not persons.

Moral concern about the nature of mankind impinges upon consideration of IVF in two quite different ways. The first is in claims that IVF is 'unnatural' and therefore morally unacceptable. In one sense - the sense that anything that occurs in nature is in fact natural - the worry is clearly unfounded for IVF is natural in that sense. Another and more important aspect of the claim is that it is part of man's nature to be a moral agent. According to such claims man therefore behaves unnaturally if he behaves immorally or amorally. While such linking of moral theory to man's nature remains of potentially profound relevance to moral philosophy (and riddled with philosophical problems) it does not afford any basis for rejecting IVF - or anything else - simply on grounds that it is unnatural, for the term used in this context becomes more or less synonymous with 'immoral' and the claim collapses into a tautology (IVF - or whatever - is immoral because it is immoral). Some independent reasoning must be adduced.

There is another way in which IVF provokes worries about the nature of mankind. IVF has made possible genetic manipulation of human embryos. If it were granted that man's nature, including his moral nature, resided at least in part in his genetic endowment, and given what is plainly true that we do not know how this is the case, then there is an obvious danger that some sorts of genetic manipulation experiments may threaten the nature of man, including his moral nature. Until we better understand what is man's moral nature and the implications of that nature for what we ought and ought not to do - that elusive holy grail of religious and secular moral philosophy - until then it would surely be wiser not to risk tampering with it. Such considerations may perhaps underpin a distinction offered by Grobstein in his useful book about these problems when he proposes some principles which should govern genetic interference with human embryos: 'First and foremost a clear statement that the objective is to preserve and not to change humanity' (7). Thus such research might be acceptable if designed to eliminate a known genetically transmitted disease in a human embryo (whose parents had objections to termination of its embryonic life). On the other hand speculative genetic research on humans designed to discover or alter (even to improve) such characteristics as intelligence, aggression, affection, or moral concern, stands more than a negligible risk of impairing or altering that elusive nature, and especially that moral nature, of human beings before we have even discovered or decided what it is. (Those who find such thoughts more appropriate to science fiction than to the current reality of genetic manipulation research would do well to recall the exponential growth rate of scientific technology and ask themselves whether it is not better to consider the possibilities sooner rather than later).

Finally there is the very important practical (and also moral) problem about what to do when people have fundamental moral disagreements. In societies where respect for personal autonomy and for 'human rights' are fundamental moral principles the usual answer is that while people may reason with each other they must allow each other to come to their own moral decisions and to act accordingly provided only that such action does not infringe upon the equal rights of others.

Unfortunately one of the central moral issues in $I V F$ research - that of the moral status of the embryo-fetus - raises precisely the question as to whether or not this condition is met. Those who believe that the fetus is morally equivalent to the rest of us and thus has the same rights are unlikely to respect the views of the other camp when to do so entails widespread acceptance of actions which they see as morally akin to murder - notably the killing or letting die of unwanted human embryos and fetuses. Conversely, those who reject the claim that the human embryo-fetus is of equal moral status with the rest of us will reject the imposition of these views when it leads to unwanted childbirth or the banning of potentially valuable scientific research on embryos.

(Continued on page 199) 
suggests that these children do not find their lives worth living. A suicide rate many times that for the community as a whole would be convincing evidence; occasional feelings of disturbance about the gaps in one's sense of identity would not be.

If, however, there is no such evidence, then a prohibition on the use of donor gametes would not be in anyone's interest - not in the interests of the child who might have been born and lived a worthwhile life, and certainly not in the interests of the parents who desire a child. Why then should society impose such a prohibition?

Similar considerations apply to the use of a surrogate mother, where a couple cannot have a child by any other means; except that here, if the couple provided both egg and sperm, the child would have no problems about knowing its genetic parents. They would be its social parents as well. I cannot believe that, later on, the child would be greatly disturbed to learn that it spent nine months in the womb of another woman. This is different only in degree from learning that one had a wet nurse to whom one was, for a time, much closer than to one's mother.

Finally, I cannot understand the insistence on the point that in vitro fertilisation 'circumvents' childlessness rather than remedying the primary disability. I happen to be short-sighted. It would be nice if medicine could remedy this disability, but given that it appears to be difficult to do so, I am extremely glad that by wearing glasses I can circumvent my problems. I would not be at all appreciative if the next time I needed a pair of glasses, I was told that none were available, because the resources needed to manufacture them were being put into a search for some method of remedying short-sightedness. I would be especially angry if, upon enquiry, I learned that the prospects of this search producing quick results were very slim. That is, unfortunately, the situation with attempts to remedy many of the primary causes of infertility; so infertile patients could justifiably be angry if attempts to 'circumvent' their problem were indefinitely postponed in order to find remedies for the causes of their condition.

\section{References}

(1) Rowland R. Attitudes and opinions of donors on an artificial insemination by donor programme. Unpublished typescript available from Dr R Rowland, School of Humanities, Deakin University, Victoria, 3217.

\section{(Continued from page 188)}

In such conflicts the normal processes of representative democracy, though they can permissively ensure the right of each side to behave themselves as they believe it proper to behave, can find no solution which will appear just to both sides, for in effect one side is bound to impose its views upon the other, as assessment of the various legislative possibilities rapidly demonstrates. The only glimmer of hope that may be offered to those whose views are rejected is that in a democratic society they constantly are given the opportunity to persuade their fellows of the errors of their opponents' ways. Part, at least, of such persuasion involves the deployment of moral reasoning about the relevant issues.

\section{References and notes}

(1) See for example Reidy $M$. Ethical issues in reproductive medicine: from the perspective of moral theology. In: Reidy $M$, ed. Ethical issues in reproductive medicine. Dublin: Gill and Macmillan, 1982: 120-122.

(2) A good presentation of this view is given by Sumner $\mathrm{L} \mathrm{W}$ in his Abortion and moral theory. Princeton: Princeton University Press, 1981: especially $\mathrm{Ch} 4$.

(3) Singer P. Animal liberation. New York: Avon Books: 1977: especially Chs 1 and 6.

(4) Locke J. An essay concerning human understanding. London. Originally published in 1690 . See for example Dent's Everyman's Library Edition. Book 11, Ch 27, espicially section 9.

(5) Tooley M. Abortion and infanticide. Philosophy and public affairs 1972: 2; 37-67.

(6) Harris J. In vitro fertilisation: the ethical issues. The philosophical quarterly 1983; vol 33, no 132; 225-226.

(7) Grobstein C. From chance to purpose. Reading, Massachusetts: Addison-Wesley publishing company, 1981: 146. 